\title{
El latín vulgar y la formación del castellano (1)
}

El Castellano procede del latín, lengua del Lacio,-tierra estrecha tendida al sur de la desembocadura del Tiber, en Italia-y que pertenece, junto con el umbrio-samita, a la rama itálica de la gran familia aria. Es pariente, por lo tanto, de los idiomas de los indos, persas, griegos, celtas, germanos y eslavos. El latín tuvo orígenes muy modestos, pero fué engradeciéndose junto con el pueblo que lo hablaba hasta alcazar su apogeo con el último siglo de la República y con el esplendor del Imperio. Su ámbito se extendió a medida que se extendia políticamente el Estado Romano y perduró aún después de la caida de dicho Estado, como lengua de la Iglesia (Latín Eclesiástico) y como lengua de los doctos de la Edad Media (Baja Latinidad). El territorio sobre el cual imperó el latín se llama Romania; las lenguas modernas a que dió origen, romances y la ciencia que estudia los problemas comunes a todos éstos, Lingiiistica Románica. Las lenguas modernas derivadas del latín son las siguientes, comenzando por el Oriente:

a) el Rumano, hablado en Rumanía y por grupos dispersos en Besarabia, Macedonia, Salónica y otros lugares

(1) Ensayo de sistematización didáctica. 
próximos. Tiene la particularidad de ser lengua románica por su estructura gramatical no obstante poseer más del cincuenta por ciento de palabras eslavas en su vocabulario.

b) El Retorromano o Rético, hablando a lo largo de los Alpes, entre las fuentes del Rhin y el mar Adriático forma tres islas idiomáticas. No alcanzó gran desarrollo, cuenta con escasas y pobres obras literarias, y está muy influído por las lenguas vecinas alemán e italiaño.

c) El Italiano, hablado en Italia e islas italianas, es el más próximo al latín por ser heredero directo de éste y haber luchado con otras lenguas que eran asimismo dialectos románicos.

d) El Provenzal, hablado en el sur de Francia, en una comarca profundanente romanizada, la Galia Narbonesa, dió origen a una brillante literatura lírica que irradió sobre Europa a fines de la Edad Media. Es lengua culta y muy evolucionada.

e) El Francés, hablado al principio solo en la Isla de Francia, comarca cuya capital es París, terminó por imponerse paulatinaninte talestatros didecotos hasta ser la len-

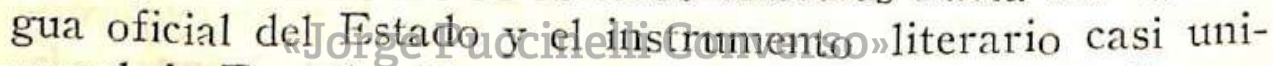
versal de Francia. En su constitución iníteriia es la lengua romance más distanciado del tipo central latino aunque su vocabulario, especialmente en lọs cultismos, es muy roṇánico.

f) E1 Catalán, hablado con sus varieclades o modificaciones secundarias, en España, en Cataluña, Valencia y las Islas Baleares y en Francia en la provincia de Rosellón, es lengua antigua y fecunda en creaciones literarias. Está organizada con los mismos elementos del castellano, aunque con mayor vocabulario griego poptular y menor vocabulario árabe. Su más próximo parentesco es el de las de- 
más lenguas hispánicas, pero tiene tambiéii mucha semejanza con el provenzal cuya influencia le da acentuado carácter.

g) El Gallego-Portugués, hablado en España en Galicia y con pocas variantes, en Portugal y Brasil, es lengua más antigua que el castellano y alcanzó antes que éste madurez literaria. Fué el idioma de la poesía lírica de los mismos poetas castellanos en tiempos en que éstos encontraban todavía rudo su propio idioma. Está organizada también con los mismos elementos del castellanio, coń morfología y vocabulario muy próximos. Se caracteriza, principalmente, por una distinta evolución de su sistema de consonantes.

h) El Castellano o Español, hablado en España, en Ibero-América y en las Islas Filipinas como lengua oficial y como casi único instrumento de la literatura, es el idioma romance hablado por un mayor número de personas (aproximadamente cien millones) y el idioma europeo extendido por el muindo que ha conservado mayor unidad, pues son escasas, relativamente, sus diferencias regionales en fonética, morfiglogía, sintaxtis ye rocabulario.

Pero los idiomas romances no proceden directamente del latín sino del latin untgar y cuando se quiere fijar exactamente sus orígenes es indispensable conocer las características y el papel desempeñado por esta lengua. Cuando se dice latín, se entiende por lo general el latín clásico o sea la lengua escrita que aún admiramos en las obras maestras de aquella ilustre literatura, particularmente en Cicecerón, Virgilio, Horacio y demás ingenios de la Edad de Oro. El latín vulgar, en cambio, era lengua que sólo se hablaba. Inicialmente, como es natural, no hubo sino un latín: el de la primitiva Roma y su comarca circundante, lengua de campesinos, impregriada de esencia agraria que hizo lle- 
gar hasta sus lenguas descendientes, donde egregio, que significa ilustre, se expresa con un sufijo negativo y la raíz de gregem, rebaño; y carácter, que significa profunda realidad del espíritu, se expreșa con la raíz de character, marca material y particularmete marca del ganado. Este idioma sencillo se fué complicando a medida que se desarrollaba la cultura que lo tenía como instrumento de relacióni y de arte. La Roma simple de los primeros tiempos fué luego la Roma de las clases sociales con sus senadores, caballeros, plebeyos, esclavos, libertos, con sus costumbres refinadas y sus artes y sus letras desenvueltas. De esta evolución surgió la diversidad de lenguas. Se diferenciaron, desde luego, el idioma de las clases elevadas y el de las clases inferiores, el idioma de la ciudad y el idioma de las aldeas. Pero la más profunda ruptura se produjo entre el idiona hablado y el idioma escrito. El gusto literario impuso para la composición un lenguaje más pulido, el serme politior, sujeto a mayor número de reglas gramaticales, severo, purista y estático. Durante toda la historia de las letras latinas, el genio romano se esmeró en darle mayoriblilezace astelengtaje. Thasta convertirlo en un dechado déarmoníaciperio cacentuando al mismo tiempo su separación de la vida, su realidad de exquisito artificio. Llegó un momento en que su morfología y su sintaxis tenían que aprenderse, como se aprenden hoy, para ser aplicadas a la prosa y el verso y eran el privilegio de los grupos cultos. El lenguaje hablado o vulgar, el sermo vulgaris, era en cambio un sistema mucho más libre, vital y dinámico. El nombre de vulgar no le viene por ser propio de la plebe o de los barrios bajos, ni por ser el lenguaje descuidado de las campañas, sino por ser el que se hablaba en la vida ordinaria, como algo vivo, espontáneo y vernáculo, mientras que el latín clásico no se hablaba sino por excepción, y con el es- 
tilo oratorio, en las grandes solemnidades públicas. Y cualquiera que hablase en esta forma extraordinaria el latín clásico, pongamos por ejemplo a Cicerón en el Senado, hablaba luego el latín vulgar en sus conversaciones de familia o de negocios, en la vida común. A medida que transcurrían los años las características diferenciales se iban acentuando. El latín vulgar es así la primera rama desprendida del latín clásico y constituída a su vez en tronco independiente, origen inmediato de la ramificación que representaron los romances. Por lo tanto, interesa a la historia de éstos el conocimiento del latín vulgar, tanto como el del clásico. Dicho conocimiento constituyó una incógnita para la ciencia lingüística por mucho tiempo debido al carácter de lengua puramente hablada que tuvo el latín vulgar, con cuya desaparición desapareció también su memoria. La moderna erudición, sin embargo, ha reconstruido por paciente inducción toda s11 estructura y ahora podemos contar con gramáticas en que se describe minuciosamente dicha lengua.

Las fuentes de que se han valido los lingüistas para la reconstrucción del latin vulgar han sidg según Grandgent ( I) las relaciones hechas por los gramáticos y los glosarios gramaticales de formas incorrectas; algunos textos escritos por personas de escasa cultura y las faltas ocasionales cometida's por los autores cultos; y lo más importante que todo, los subsiguientes desarrollos de las lenguas romances. Los gramáticos del latín clásico, con el objeto de preservar dicha lengua de influencias extrañas se refieren con frecuencia a ciertos errores que deben evitarse y que son propios del latín vulgar, con lo cual, indirectamente, describen a éste. Este mismo propósito de limpiar la lengua clásica, induce a los gramáticos a elaborar y publicar glosarios o

(1) H. Grandgent. Latín Vulgar.

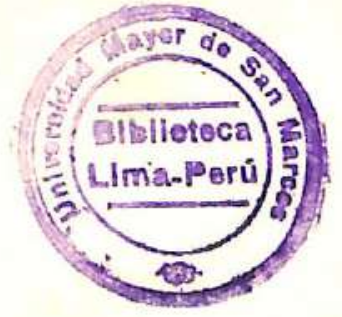


listas de voces y grafías incorrectas provenientes del latín vulgar, acompañadas de las respectivas voces y grafías correctas. El más famoso de estos glosarios es el Appendix Probi, redactado hacia el siglo III a. de C. Ejemplos de correcciones del Appendix Probi:

\section{speculum non speclum \\ calida non calda \\ ansa non asa}

camera non cammara

De estas correcciones inferimos que en latín vulgar se decía specium, calda, asa, cammara, y conocemos por tanto no solamente considerable cantidad de voces sino su tendencia gramatical, pues las supresiones y cambios de letras que hay en Tas palabras citadas son síntomas de corrientes generales de transformación. Los textos escritos por personas de escasal cultura son singularmete útiles, pues no habiendo sus autores llegado a dominar el latín clásico, escriben en gran partesegún fórmulas que oyen, es decir perennizando preciosos tragmentos del latín vulgair. Es muy valiosa," "en" este sentido, la Peregrinatio ad Loca Sancta narración de un viaje a Tierra Santa, compuesta por una anónima ignorante de las reglas rigurosas del latín clásico, y que se presume sea una monja española que redactaba para sus hermanas en religión. Es de fines del siglo IV de nuestra era. De la misma época, poco más o menos, es la Mulomedicina Chronis, libro de veterinaria, escrito con igual ignorancia, y que compila antiguos y famosos principios sobre la especialidad. Está firmada por "Claudius Hermeros veterinarius". Constituyen una apreciable fuente de estudio, asimismo, las "inscripciones hispanolatinas" o sean epitafios en lápidas sepulcrales de Es- 
paña, redactadas por gente sencilla, en memoria y elogio de sus deudos. Son breves, por lo general, pero muy ilustrativas. Pero como se ha dicho, el campo más interesante de todos es el que proporcionan los subsiguientes desarrollos de las lenguas romances. En efecto, estudiando los idiomas que siguieron al latín vulgar en toda la Romania y estudiándolos de preferencia en aquel estadio inmediato, se encuentra que todos ellos tenían muchos fenómenos comunes y que sin embargo no aparacen en el latín clásico, lo que quiere decir que eran privativos del latín vulgar. La lingüística románica ha realizado esta labor comparativa y de sus investigaciones, así como del auxilio que prestąn los textos antes mencionados se ha podido precisar la completa estructura de lo que antes era un idioma problemático. Quedan todavía muchos aspectos por investigar, pero la etapa esencial está vencida.

Comparado el latín vulgar con el clásico, saltan diferencias que habían sido observadas ya desde la Edad de Oro. La más notable de ellas es la tendencia analítica del latín vulgar o sea ê purito de manifestam elspensamiento de modo más expliçitor con un may monumero de palabras en contraste con el latín clásico, idioma esencialmente sintético. Encontramos así en la construcción del latín vulgar un desarrollo enorme de artículos, preposiciones, prefijos, sufijos y otros elementos determinantes y modificantes. Esta tendencia analítica, qué fué luego trasmitida en herencia a los romances, se percibe de manera preferente en la eliminación sistemática de las declinaciones del sustantivo para expresar los casos por medio de preposiciones. Las distinciones casuales se hacían en el latín clásico por medio de la desinencias que se añadian a la raíz temática. En el sustantivo dominus (señor), por ejemplo, las variantes de 
la desinecia van indicando los seis casos del siguiente modo, para el singular: domin-lts (nominativo); domin- $i$ (genitivo') ; domin-o (dativo); domin-un (acusativo) domin-o (ablativo); domin- $e$ (vocativo). De estas distinciones casuales, por desinencia morfológica, el latín vulgar solo mantuvo las correspondientes al nominativo y el acusativo. $\mathrm{Pa}$ ra expresar los demás casos recurrió a las preposiciones, tal como hacemos en la declinación romance. Así en vez de urbs Romae se dijo urbs de Roma; en vez de marmoreum. templum, templum de marmore. El adjetivo perdió parte considerable de su sistema comparativo y superlativo al abandonar las terminaciones sintéticas ior e imus como consecuencia de lo cual se decía: magis aptus en vez de aptior (más apto que); multumbonus en vez de optimus (el más bueno entre todos). Eleverbo varió también sus formas sintéticas trocándolas por otras analíticas, lo que dió ocasión al nacimiento de las formas compuestas de la conjugación que eran extrañas al latín clásico. 'Así, la forma simple pasiva amabantur fué sustituída por la perifrasis erant amati Bebahicatardasole laeforan simple del futuro amabo por lașopetífrasisinchinareo hrabego (amaré). La mayor flexibilidad del latín vulgar con respecto al latín clásico se demuestra por la gran riqueza de aquel en derivados y compuestos. La lengua clásica había perdido, mientras tanto, su facilidad para formar nuevas voces; pero el habla vulgar la conservó y aumentó. Posé́a para ello gran cantidad de prefijos y sufijos. $A d$, con, $d e$, dis, ex, in, re, eran activamente aplicados en la creación de palabras nuevas: adpreciare, confortare, cominitiare, defamatus, disfactus, exaltare, inanimatus, recapitulare; lo mismo que otros varios prefijos. Los sufijos como ela, itas, itus, bilis, osos, arius, tenían también activa aplicación: clientela, agilitas, 
inviolatus, irritabilis, ponderosus, sanguinarius. En cuanto al material sonoro se diferencia el latín clásico y el vulgar porque en éste adelantan algunas transformaciones que van a hacerse más radicales en los romances. El latín clásico distinguía diez vocales por la menor o mayor extensión que se le daba a la unidad de tiempo de su pronunciación.

Las cinco vocales fundamentales podían de este modo ser "breves" o "largas": $a, e, i, o, u$ breves; $a, e, i, o, u$, largas. Esta cantidad vocálica del latín clásico se convirtió en calidad articulatoria en el latín vulgar. En esta lengua no se hizo la distinción de las vocales por su mayor o menor extensión sino por su articulación cerrada o abierta. Las vocales largas se convirtieron en cerradas y las breves en abiertas, desde un punto de vista articulatorio, unificándose en la cantidad. En general, las vocales son letras abiertas; de modo que la calificación de cerradas corresponde solamente a la condición relativa de menos abiertas. Las breves, convertidas en abiertas, adquirieron por tal circunstancia la inminencia de los cambios más profundos que se

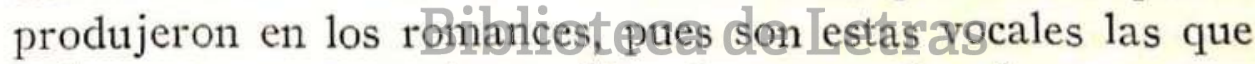
sufren mayor transformaoiónciale pasanaeląs "lenguas modernas. Muchos de los cambios fonéticos de las consonantes se preludian también con el latín vulgar. La $h$ se convirtió en muda desde el siglo I a. de C. $S$ inicial requirió una vocal como apoyatura: spiritum, espiritu; sposa, esposa. $M$ final se convirtió en $n$ : tam, tan; quam, quan. La $n$ ante s se perdió mensam, mesa; ansam, asa. El tránsito de g $y d$ hacia su desaparición estaba bastante avanzado como se puede ver en las formas de, di, ge, gi ante vocal convertidas en y: podium, poyo; corrigiam, correya. Y cosa parecida se puede decir de las demás letras consonantes que varían del latín al castellano y que alcanzan en el latín vul- 
gar estados preparatorios o intermedios. Otro aspecto interesante que caracteriza al latín vulgar es el relativo al vocabulario. Esta diferencia separa a ambas lenguas no ya desde un punto de vista formal sino de fondo, en su contenido semántico. Siempre ocurre que las lenguas cultas y elegantes toman para sí un vocabulario escogido que difiere del vocabulario vulgar; pero esta separación se acentuó más en el latín por el carácter exclusivamente literario del latín clásico que lo obligaba a disponer de gran número de figuras poéticas, y términos abstractos y técnicos, desconocidos para el vulgo. Con todo, la divergencia estaba lejos de ser absoluta y el mayor número de vocablos se usaban parejamente en ambas lenguas. La siguiente clasificación de Grandgent, comienza precisamente por este sector de palabras: I ) Palabrasusadas igualmente on el latín clásico y en el zulgar.2) Palabras usadas diferentemente en el latín clásico y en el vulgar. 3). Palabras usadas en el latín clásico peroono en el vulgar. 4) Palabras usadas en el latín vulgar pero no en el clásico. Al primer grupo pertenece el caudal mảs tnmarosa y qutieaconstituye el núcléo del idioma. Porvejeriplociffilhis, onatensopater, panis, bonus, viride, amare, andire, dicere, quando, si, in. A.l segundo grupo pertenecen muchas palabras que cambian su significado entre una lengua y otra debido principalmente a los fenómenos de restricción y extensión del sentido y que se deben a conocidas leyes semánticas. En la restricción las palabras que antes expresaban algo muy amplio y general ahora se especializan en algo definido y concreto. Ejemplos: mulier (mujer) adquiere el significado de esposa; cognatus (deudo consanguíneo.) adquiere el significado de cuñado. Por la extensión, se produce el proceso contrario. Ejemplos: parentes (padres) adquiere el significado 
de parientes; viaticum (provisión para el viaje) adquiere el significado de viaje. Al tercer grupo pertenecen numérosas palabras del latín clásico que no fueron jamás empleadas en el latín vulgar o que, en caso de haberlo sido estaban ya en completo desuso al principiar la: formación de los romances. No han pasado, por lo tanto, al léxico popular de éstos; y si las encontramos en ellos es debido a transmisión erudita de los libros acaecida más tarde. Ejemplos: funus (funeral); jubere (mandar), proles (descendencia). Muchos adverbios y conjunciones se encuentran en este grupo y se consideran desaparecidos para las lenguas romances como antem (más, pues, pero), ergo (luego, pues, así) quoad (hasta que) postquam (luego que) saltem (por lo menos). 'Al cuarto grupo pertenecen las palabras que se usaban en el latín vulgar pero no en elclásico por ser de su propia creación o haberlas incorporado del latín clásico al tiempo que éste las desechaba. Este caso es el más corriente. Cuando el latín clásico disponía de dos palabras sinónimas o casi sinónimas, optaba generalmente por una sola, la que juzgaba más de açęł dōicon su psicologíanculta. El latín vulgar, en cambio, hacia la selección inversa de ahí una diferenciación de vocabulario cuya consecuencia ha sido alejar más a los romances del latín clásico. La lista puede ser muy larga pero la vamos a reducir a algunas formas muy sencillas, por las que se verá que las voces escogidas por el latín vulgar son que encontramos en el habla popular castellana:

LATIN VULGAR

Alter

bucca

causa

\section{LATIN CLÁSICO}

alius (otro)

os (boca)

res (cosa) 


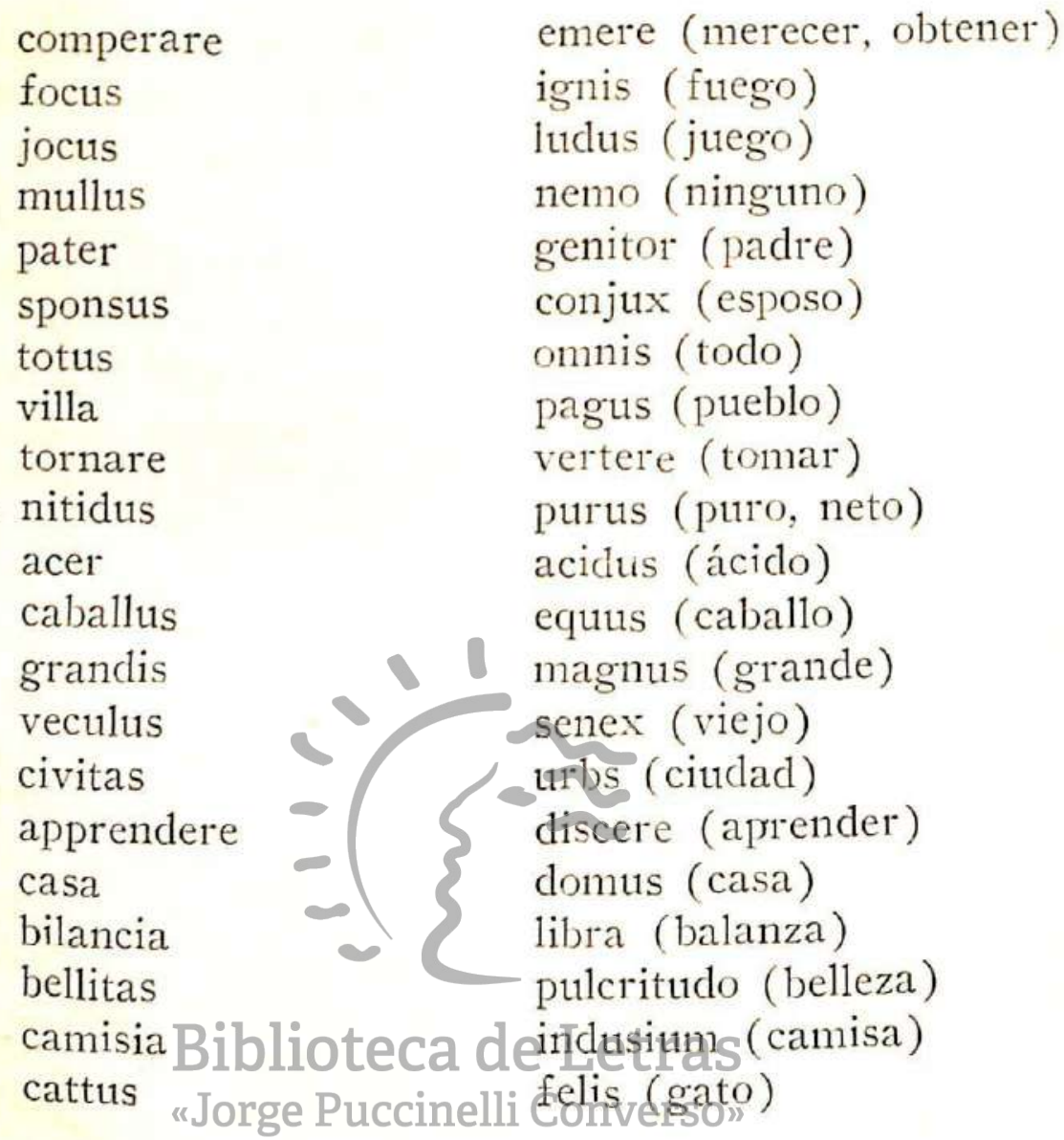

'A todas las noticias anteriores debemos añadir la diferencia de construcción entre el latín clásico y el vulgar. Aquel perseguía fines estéticos y alcanzó más complicación. Este perseguía fines lógicos y alcanzó más sencillez. En la lengua familiar se busca la comunicación rápida y en consecuencia se eliminan las volutas de arte que pueden oscurecer el sentido o demorar su recta comprensión. 'Así se obliga a unir siempre lo que racionalmente debe estar unido como la preposición y la palabra regida o el sustantivo y el adjetivo modifcativo que en la lengua literaria se separaban por arbitrariedad de gusto o escuela. 
A España llegaron ambos latines. Iniciada la conquista romana en 206 a. de C., la península ibérica comenzó a recibir tanto colono incultos que solo conocían el latín vulgar, como altos funcionarios, juristas y maestros de retórica que difundieron el latín clásico e hicieron de España un brillante foco de las letras romanas. Grandes escritores de la Edad de Plata fueron españoles como Seneca, Lucano, Marcial y Quintiliano. El latín clásico continuó en España, como en los demás países románicos, su destino de lengua pulida pero inerte, y luego de alcanzar aquel florecimiento se convirtió en el bajo latín o idioma decadente de los doctos medioevales, mucho menos refinado y artístico que su predecesor e influenciado con fuerza creciente por el latín vulgar. El latín vulgar en cambio, que en Roma misma era ya mucho más flexible y cambiante, con la separación de la metrópoli y luego con la caída y ruina de ésta, aceleró el proceso de sus mutaciones hasta alcanzar completa independencia y nuevo carácter en el castellano literario del siglo XII. A1 bajo latín no le contintó lengua ninguna y su muerte, al preferirse el pomanee énollengtat literaria, clausura

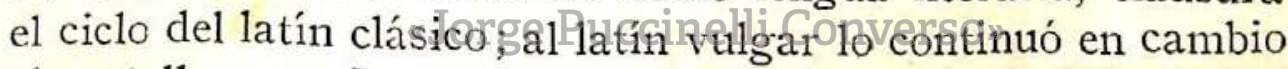
el castellano en España y las demás lenguas modernas en el resto de la Romania y su ciclo se prolongó en ellas por insensible y divergente graduación. Ya en un documento de la Edad de Oro de las letras romanas se señala la pronunciación dialectal acentuada que comienza a adquirir el latín vulgar de España. Más tarde Plinio se refiere a una palabra propia usada en España, formaceos, de donde se deriva hormazo del castellano moderno que significa pared hecha de tierra. El Arzobispo de Sevilla San Isidoro, en sus Etimologías, en el siglo VII de nuestra era, nos explica voces exclusivas de España en forma que se puede presumir 
la gestación de una nueva lengua. Esta gestación se acentúa durante las centurias X y XI. Mientras en Francia, bajo la influencia del ciclo cultural de Carlomagno se reacciona a favor del latín y se purifica la lengua escrita de formas romanceadas, en España continúa la prosa latina de inspiración clásica siendo mellada por el romance, lo cual sirve para conocer no solamente la degeneración del latín escrito sino, a través de éste, la evolución del romance. A fines del siglo XI los cultos monjes de la Orden de Cluny, y particularmente los del convento de Sahagún, inician una reacción vigorosa, pero tardía, la cual detiene soio por el momento el proceso. Las fuentes para el estudio del español naciente por aquellos sigios son los "diplomas" o documentos notariales y las "glosas" o acotaciones hechas a códices religiosos. En diplomas del siglo $\mathrm{X}$ aparecen ya algunas formas peculiares del castellano. Queriendo escribir en latín, los notarios se traicionan y deslizan palabras castellanas. Existe una escritura de donación fechada en 938 en que se utilizan las palabras castellanas prado, pozo, kareira (carrera). Las "Glosas," principales son dos: las "Emilianenses"Jgrias "Sheinsel", Co fueren"elaboradas en los monasterios benedictinos de San Millán de la Cogolla, en Rioja, y de Santo Domingo de Silos, en Burgos. E1 contenido de los códices son sermones y doctrina y ejemplos ascéticos. El arte del "glosador" consiste en colocar las palabras romances correspondientes al texto latino, a veces al margen, a veces en la interlinea y en ordenar, mediante las letras $a, b, c, d \ldots$ Ios elementos de la oración latina según la precedencia de la construcción castellana, a fin de que el lector entienda fácilmente. Ejemplos de las "Glosas Silences": usque in finen (texto latino) ata que mueran (glosa castellana); post circulum anni (texto latino) por 
lo anno pleno (glosa castellana); procuratores (texto latino) : serviciales (glosa castellana) (I). En los diplomas y en las "glosas" hay que buscar las primeras manifestaciones del castellano y no en los "Fueros" o concesiones de privilegios que los Reyes otorgaban a las ciudades, como el famoso de Avilés (Siglo XII) que ahora se consideran en gran parte apócrifos o mal copiados.

José Jiménez Borja.

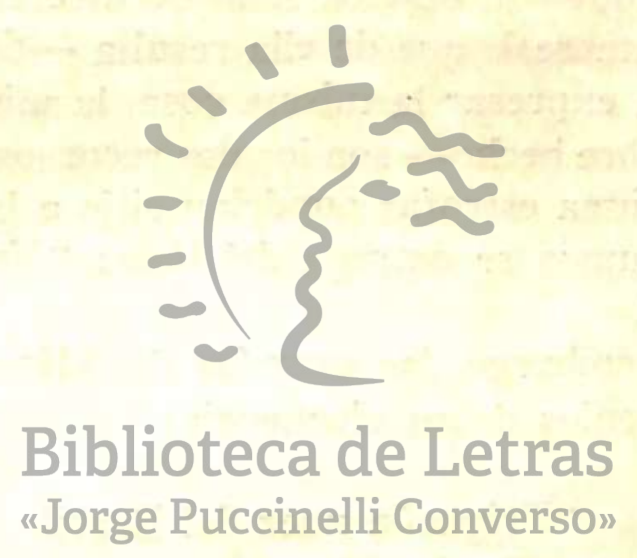

(1) Ramón Meléndez Pidal. Orígenes del Español. 